\title{
INVESTIMENTO EM CRÉDITO DE DESCARBONIZAÇÃO - CBIO
}

\author{
INVESTMENT IN DECARBONIZATION CREDIT - CBIO
}

\author{
Raphael Inácio de Jesus Almeida ${ }^{1}$
}

RESUMO: Este trabalho tem como objetivo central de demonstrar os fatores que envolvem o investimento em Crédito de Descarbonização (CBIO). E os objetivos específicos são: desenvolver um construto dos resultados das análises, de diferentes autores, efetuadas e publicadas, sobre o tema: economia e sustentabilidade, a partir de pesquisas aplicadas ao ambiente organizacional e suas relações com o mercado, no sentido da obtenção de caminhos para a conquista de vantagens competitivas para as empresas. Para tanto, será embasado os fatores que se referem a comparação das premissas de como os autores selecionados definem referenciais de competitividade; identificar um padrão de desempenho condizente com a realidade da sociedade contemporânea. A metodologia apresentada neste trabalho foi qualitativa com viés descritivo.

Palavra-chave: Investimento. Sustentabilidade. CBIO. Economia.

\section{INTRODUÇÃO}

A combinação da ética, em sua visão clássica, com um tema mais atual, a sustentabilidade e seu diferencial competitivo compõe um tema emergente de literatura ainda escasso, o que dificulta a criação do portfólio para estudo, análise e formulação de ideias. O mundo do trabalho, está submetido a transformações sob as exigências até então desconhecidas, fazendo com que organizações revejam as relações entre indivíduos e à atividade que exerce e o trabalho que desempenha. Dessa forma, a questão ética dentro da área empresarial, está relacionada com o que cada indivíduo, e cada grupo de indivíduos se posicionam em sociedade.

A ética empresarial está presente nas relações organizacionais, na competitividade de suas ações, na formação da identidade e da imagem criada, na

\footnotetext{
${ }^{1}$ Engenheiro Eletricista formado pela Universidade Anhanguera - RJ. Pós- Graduado em Gestão Financeira pela Faculdade ESPG - PR. Pós Graduado em Energias Renováveis pela Faculdade Interclasse - MG. Atuante no setor elétrico desde 2003, passando por concessionárias de energia, construtoras civil e industrial, e desde 2013 atuando no setor de energia solar fotovoltaica a frente da Rcatec Engenharia. E-mail: raphaelialmeida@gmail.com.
} 
representatividade de suas ações e opiniões para a sociedade. Sendo assim, pode-se associar questões morais e éticas com o desenvolvimento sustentável.

Logo questões problemáticas são levantadas: A sustentabilidade e a ética são consideradas diferenciais no setor $d a$ qualidade $e$ competitividade para as organizações? Espera-se a utilização de indicadores que forneçam medidas comparativas em relação a um padrão proposto à partir de teóricos relacionados a temática abordada.

Sua relevância é denotada sob o viés de contribuições teóricas e práticas, associadas à promoção da gestão. Sob o aspecto teórico, contribuições à revisão da literatura sobre ao que se refere as questões pertinentes a economia e sustentabilidade realizada sobre um portfólio de livros e artigos selecionados por meio de um processo estruturado e sequencial.

Ainda sob o aspecto teórico, uma proposição de metodologia sistematizada para o desenvolvimento das etapas de identificação, organização, mensuração, avaliação e proposição de ações de aperfeiçoamento para a gestão de processos organizacionais. Sendo assim, é possível ver a importância devido ao fato de não existir um modelo para avaliar o progresso na questão ética e a sustentabilidade nas empresas.

Dessa forma, o Ministério de Minas e Energia (MME) publicou no Diário Oficial da União (DOU) ontem, 2I, a Portaria MME 419/19, assinada pelo ministro de Minas e Energia, Bento Albuquerque, que regulamenta o Crédito de Descarbonização - CBIO.

Esse crédito faz parte da Política Nacional de Biocombustíveis - Renovabio, que visa à produção sustentável de biocombustíveis no país, beneficiando duplamente o consumidor com a garantia de abastecimento e a oferta de combustíveis mais baratos. O CBIO também beneficia os produtores de biocombustíveis que buscam formas de produção mais eficientes e, consequentemente, poluem menos o meio ambiente.

CBIO - Crédito de Descarbonização é um ativo ambiental emitido pelo produtor ou importador certificado de biocombustíveis por meio de bancos ou instituições financeiras. Uma unidade de CBIO corresponde à emissão evitada de uma tonelada de carbono no meio ambiente. 
Após sua emissão, os CBIOs podem ser negociados em ambiente de negociação no qual está prevista a compra e venda de créditos entre produtores, distribuidoras de combustíveis e demais investidores.

Esse regulamento é a última ação do MME antes da plena operação da RenovaBio em janeiro de 2020. Com isso, o Brasil poderá oferecer no mercado financeiro o ativo ambiental que sustenta o maior programa de descarbonização do planeta: o RenovaBio. O mercado de CBIO representa a solução de economia de baixo carbono que as maiores empresas do mundo procura

\section{DESENVOLVIMENTO}

\section{I RESPONSABILIDADE SOCIOAMBIENTAL NAS ORGANIZAÇÕES}

Segundo Laasch e Conaway (2016), temas como: o papel do indivíduo, o sentido de viver, o equilíbrio no uso dos recursos naturais, o respeito pelas minorias tomou corpo ultimamente e passou a pautar as organizações indicando certo esgotamento do modelo de negócios até então em vigor. Em decorrência do novo cenário reflexões sobre valores e atitudes vieram à tona, em uma vigilância ética que extrapolou o indivíduo, ecoando na sociedade, que passou a ser mais vigilante.

Conceitos como liderança, participação, parceria, cooperação, comprometimento, moral, sustentabilidade, responsabilidade social e outros princípios democráticos ilustram, já há algum tempo, os discursos gerenciais e possibilitam entender a complexidade das organizações, do comportamento humano e das práticas gerenciais. (GIBSON et al, 2006).

De acordo com Gibson et al (2006) essa mais recente abordagem nas organizações veio se somar à temática do lucro, da produtividade, do prazo, da meta, da concorrência e outros princípios capitalistas e vem transformando gradativamente a cultura organizacional.

Conforme Laasch e Conaway (2016) a importância da conscientização da sociedade sobre a preservação ambiental e a sustentabilidade da vida no planeta é de conhecimento de todos, razão pela qual é crescente o questionamento das pessoas sobre o que se deve ou não fazer a respeito para a preservação da natureza em prol de uma vida futura melhor. A sociedade está buscando um novo estilo de vida, que respeite os 
limites da natureza, agregando para isso mudanças comportamentais e atitudinais importantes.

Tamayo et al. (200o) consideram que os indivíduos que "existem" pelo trabalho, e trabalham conforme valores e princípios da cultura organizacional são reconhecidos conforme os resultados que agregam, pelo seu trabalho, aos objetivos organizacionais, portanto são incentivados a investir em contínuo aprendizado, tornando-se mola propulsora de seu próprio desenvolvimento.

É preciso que as pessoas encontrem significado naquilo que fazem no trabalho, na busca da satisfação pessoal, da autorrealização, para gerarem uma contrapartida de igual valor. Neste contexto, para os autores, valores e atitudes éticas, antes restritas a ações individuais, uma vez que a dimensão ética implica em relações reflexivas do indivíduo consigo mesmo, ressoam na sociedade como um todo.

Particularmente, no interior das empresas, diante da necessidade de resgatar o sentido do trabalho pelo homem, o discurso e o exercício da ética recobraram força levando a reflexões sobre as práticas e as realidades vividas nas empresas.

De qualquer modo, cabem ao homem a capacidade reflexiva e a realização de ações capazes de dar novas perspectivas para as formas de organização da sociedade.

Segundo Dias (2010), a principal motivação das empresas para a preservação dos recursos naturais veio das pressões do mercado, das exigências legais, da preocupação com a imagem institucional e do alinhamento com uma melhor qualidade de vida; levando-a a transformar e aperfeiçoar processos, com consequente ganho financeiro aderente a uma nova imagem conquistada pela adoção do que se denomina Sistema de Gestão Ambiental, em adoção crescente pelas empresas.

Considerando, então, o comportamento ético exercido pelos colaboradores de uma organização, na atitude de responsabilidade socioambiental desta perante a sociedade e o mercado, o tema deste trabalho proporá métodos para identificação, avaliação e qualificação dos processos organizacionais sustentáveis e alinhados à perspectiva da responsabilidade socioambiental de uma organização.

Processos estes que, pela geração e oferta de valores ao mercado, demonstrem vantagens competitivas perceptíveis pelo mercado de modo a gerar satisfação do 
consumidor, riqueza para a sociedade e lucratividade para a organização. Resultado este desejável pelas empresas e razão de sua existência para o desenvolvimento sócio responsável da sociedade da qual faz parte e principal motivação para o presente estudo. (LAASCH e CONAWAY, 20I6).

\subsection{ECONOMIA E A SUSTENTABILIDADE}

No sentido evolutivo, para Donaire (1999), o tema do ambientalismo foi se tornando presente no dia a dia das pessoas a partir dos anos 50. Nos anos 90, era presente uma consciência geral sobre a importância da conservação ambiental e com ela uma mudança posicional por parte dos organismos que passaram a se preocupar com a otimização do processo produtivo e a redução do impacto no meio ambiente.

A expressão adequada era prevenção, com o surgimento das tecnologias mais limpas e menos poluentes, e dos produtos ecologicamente corretos. É a semente para a introdução da gestão ambiental e formulação de códigos de conduta, bases responsabilidade socioambiental sustentável.

Segundo Dias (2017), consumo e meio ambiente são indissociáveis, pois é dependente da natureza. $O$ consumo é uma manifestação individual, própria de cada pessoa, sem ser uma característica inata, que se movimenta de forma dinâmica e modifica-se constantemente, por influências culturais e mutáveis, é uma ação social. A dinâmica das mudanças na sociedade leva a constantes mutações em seu comportamento provocando uma demanda crescente por novos produtos que impulsionam o sistema produtivo. A produção é resultado do consumo.

Para Serrão et al. (2014) a demanda da sociedade requer produtos com custos menores, qualidade melhor e características específicas e personalizadas, exigindo a melhoria das técnicas de produção e de gestão, com decorrentes ganhos de produtividade.

A variável ambiental, segundo os autores, tornou-se palpável e de interesse dos diferentes setores da economia, principalmente pelos financiadores desse movimento, que agora se dispõem a exigir o enfrentamento de riscos e a incentivar o uso de novas tecnologias como requisito para concessão de créditos e financiamentos. As 
organizações passaram a distribuir em seus organogramas as funções de gestão desse novo crescimento economico, o crescimento da economia verde.

Segundo Serrão et al. (2014, p. 30), a proposta do desenvolvimento sustentável surgiu quando os elementos considerados essenciais para o desenvolvimento de sociedades de consumo, baseados no aumento da produção industrial, passaram a ser questionados.

Face ao potencial esgotamento dos recursos naturais e os desequilíbrios ambientais locais e globais, percebeu-se que havia limites físicos, ambientais, sociais e culturais para o modelo de desenvolvimento que vinha ocorrendo desde a Revolução Industrial.

Os fundamentos desse conceito, segundo os autores, são: crescimento econômico, preservação da natureza e justiça social. Do ponto de vista econômico as organizações têm que ser viáveis, ou seja, sua operação deve apresentar lucro, dando retorno ao investimento privado.

Quanto ao aspecto social, as organizações devem apresentar condições melhores de trabalho aos seus colaboradores, respeitando e propiciando acesso de representantes das minorias e as diversidades culturais.

Pelo lado ambiental, as organizações devem exercer a ecoeficiência em seus processos produtivos, propiciar a formação de uma cultura ambiental interna e agir de maneira responsável. Entretanto o mais importante é que haja equilíbrio dinâmico entre os três fundamentos.

De acordo com Stoffel e Colognese (2015), o conceito d desenvolvimento sustentável coloca em xeque o modelo econômico vigente e por isso não consegue criar raízes e vingar, por não encontrar terreno fértil.

O que deveria servir de adubo para esta ideia, as propostas de sustentabilidade apresentadas pelas nações não são contundentes em relação às verdadeiras causas dos problemas ambientais vividos pela maioria da população mundial. $\mathrm{O}$ ser humano quando não entende qualquer problema ele tem dificuldade de encontrar a solução. 
Conforme Serrão et al. (2014), a proposição é que as sociedades, por meio de seus agentes econômicos, produzam para atender suas necessidades sem ultrapassar a capacidade do ambiente de sustentá-las.

A sustentabilidade passou a ser um componente essencial de um desenvolvimento que se preocupa com a qualidade do ambiente e com a qualidade de vida das pessoas.

A partir, segundo os autores, daí a vista se volta para o futuro e começamos a pensar em um desenvolvimento que seja duradouro, assumindo uma responsabilidade em relação às gerações faturas, pois, se não soubermos usar os recursos agora, a vida dos futuros habitantes do planeta pode não ocorrer.

Neste cenário complexo e rico se encontram e entrelaçam cinco dimensões principais, segundo Serrão et al. (2014, p. I9):

- Sustentabilidade social $\rightarrow$ objetiva a construção de uma civilização sem desigualdades sociais, com equilíbrio na distribuição da riqueza entre as pessoas hoje e no futuro; para isso é necessário existir a igualdade no acesso aos recursos e serviços disponíveis na sociedade;

- Sustentabilidade ecológica $\rightarrow$ propõe o uso dos ecossistemas com sua mínima destruição, possibilitando que a natureza encontre novos equilíbrios de recomposição, por meio de uma utilização que obedeça ao seu ciclo natural de vida e renovação;

- Sustentabilidade política $\rightarrow$ tem como meta o fortalecimento das instituições democráticas e a promoção da cidadania ativa - conjunto de direitos e liberdades políticas, sociais e econômicas - considerando, para tanto as necessidades dos diferentes grupos que formam a sociedade;

- Sustentabilidade cultural $\rightarrow$ busca o equilíbrio entre o respeito às tradições e a busca pela inovação, prezando e valorizando as diversidades culturais locais e respeitando as especificidades em relação a cada ecossistema, a cada cultura e loca; 
- Sustentabilidade econômica $\rightarrow$ relaciona-se à gestão eficiente dos recursos econômicos e naturais buscando o desenvolvimento, mas com equilíbrio econômico de toda a sociedade.

Segundo Serrão et al (2014, p. 24), tais dimensões são tentativas para estipular planos e metas a partir do conceito do desenvolvimento sustentável.

\subsection{INVESTIMENTOS}

O investimento pode ser definido como o comprometimento de dinheiro ou de outros recursos, no presente com a expectativa de colher benefícios futuros. Pois uma pessoa pode adquirir uma cota de ações prevendo para o futuro resultados monetários dessas ações justificando tanto a temporariedade, que o dinheiro ficou retido o quanto o risco do investimento.

O tempo que se leva para se formar, também pode ser considerado como um investimento. Pois nesse caso, o aluno deixara de utilizar esse tempo para lazer ou de rendimentos, que poderia ter em trabalhos, com a expectativa de que a sua carreira seja promissora futuramente, para justificar esse esforço e comprometimento.

Embora, estes dois investimentos têm caráter diferente, mais ambos se assemelham com uma característica central compartilhada por todos investimentos, pois gera o sacrifício de algo, na busca da expectativa de colher benefícios mais adiante.

Para a tomada de decisão de forma inicial, para se investir quando é montado uma carteira de ativos. Essas decisões devem ser tomadas em um ambiente que em geral é possível obter retornos mais altos, apenas no que diz respeito ao preço de um risco maior e em que é raro encontrar ativos com má precificação.

Segundo os autores Bodie; Kane; Marcus (2015), discorrem que de forma usual, pode-se distinguir três tipos de agentes financeiros, são estes: título de renda fixa ou de dívida, ações e derivativos. Quanto aos títulos de renda fixa ou de dívida, prometem um fluxo de renda determinado de acordo com uma formula particular.

Por exemplo, normalmente uma obrigação organizacional, passaria a garantir o recebimento de uma quantia fixa de juros em um período estabelecido.

Ainda os autores acima referenciados, afirmam que denominadas como obrigações com taxa flutuante, tendem a gerar pagamentos que dependem de taxas 
atuais de juros. Por exemplo uma obrigação pode gerar o pagamento de uma taxa de juros fixada e dois pontos porcentuais acima da taxa paga pelo tesouro nacional. A não ser que o tomador de credito seja falido, pagamentos dessa tipologia são fixos ou determinados. Por essa razão os investimentos, desse tipo, estão pautados na condição financeira do emissor.

Já os títulos de dívida são oferecidos um uma enorme variedade de vencimentos e provisões de pagamentos. De forma extremista o mercado monetário, refere-se aos títulos de renda fixa que são de curto prazo, altamente negociáveis e em geral tendem a ser de baixo risco. Exemplo de mercados monetários são: Letras de Tesouro dos Estados Unidos, ou certificados de depósitos bancários (CDB) (BODIE; KANE; MARCUS,2015)

Já o mercado de capitais de renda fixa abrange títulos de longo prazo, como as obrigações de Tesouro, e obrigações emitidas por agências federais, governos estaduais, municipais e entidades corporativas.

Essas obrigações variam entre muito seguras, em termos de risco de inadimplência ex. títulos do tesouro, a relativamente arriscadas, exemplo obrigações de alta rentabilidade e baixo custo. Ela também tem a sua criação com provisões extremamente diversas com relação ao pagamento oferecidos aos investidores e a proteção contra a falência do emissor (BODIE; KANE; MARCUS,2015)

Segundo Dias (2014) ressalta a existência de vários tipos de investimentos. Mas, deve se atentar que nem todos dispõem de pouco risco, segurança entre outros fatores que são condizentes ao perfil de um investidor cauteloso. Dessa forma, é determinante que o pequeno investidor, tenha o conhecimento, dos melhores tipos de investimentos, e quais se enquadram melhor com a sua realidade do investidor.

Segundo o autor Domingos (2013), afirma que, notadamente, de forma divergente da renda fixa onde tem a previsibilidade do retorno do investimento. Nos casos da renda variável os investimentos detêm a existência das oscilações com ausência de previsibilidade, onde possuem determinações mercadológicas, entre outras que são difíceis de ser mensuradas ou verificadas. 
Dessa forma, pode ser evidenciado o seu índice de alto risco, mais o seu retorno é maior. Quando se trata de investimentos, quanto maior o risco, maior é seu retorno. Assim se faz necessário, a geração de equilíbrio desses fatores que impactam na escolha de um determinado investimento. Os investimentos mais conhecidos neste aspecto, segundo Diniz (2014) são:

1) Fundos Imobiliários

2) Ações

3) Mercado de Opções

Um dos impactos que mais atingem esses investimentos é a lei da oferta e da demanda. Que determina o quanto um investimento tem mais procura, neste caso o seu valor aumenta, se não houver procura, o ativo perde valor de mercado.

O ganho desse tipo de investimento está ligado em identificar os ativos que estão supervalorizados para adquirir ou aguardar a valorização, deste. Pois a ideia é comprar um ativo com preço baixo e vende-lo, quando o mesmo tiver aumentado de valor, essa diferença é o lucro do investidor. Para encontrar o preço ideal, os investidores (traders) utilizam de análise gráfica e/ou fundamentalista.

Diferentemente de títulos de dividas, no caso das empresas, se utilizam de ações ordinárias ou participação acionaria, representando uma participação na propriedade da corporação. Não é garantido, nenhum pagamento aos acionistas, e sim, eles recebem qualquer dividendo que a empresa possa pagar e tem participação proporcional aos ativos reais de uma empresa. Se a empresa tiver sucesso, o valor do patrimônio aumentará, se ocorrer o contrário, este diminuirá (BODIE; KANE; MARCUS,2015).

Nesse sentido, o desempenho dos investimentos das ações está diretamente associado ao sucesso da organização e a seus ativos reais, que podem ser definidos como a somatória do patrimônio da empresa, normalmente são evidenciados no balanço patrimonial da empresa. Pode-se observar que, por essa razão os investimentos e ações tendem a ser mais arriscados do que os títulos de dívida.

De acordo Mendes (2018) retrata que os títulos derivativos, como opções e contratos de futuros, oferecem retornos que são determinados pelos preços de outros 
ativos, como o preço de obrigações ou de ações. Por exemplo uma opção de compra para uma ação de uma empresa pode se revelar sem valor, se o preço da ação dessa empresa permanecer abaixo do valor do exercício, mais pode se tornar mais valiosa se passar desse nível que pode ser de U\$ 20. Os títulos de derivativos têm essa denominação porque o seu valor deriva do preço de outros ativos

Segundo os autores Bodie; Kane; Marcus (2015), retratam que o preço das ações é um reflexo da avaliação coletiva dos investimentos, sobre o desempenho atual de uma empresa e a sua perspectiva futura. Quando o mercado está em uma fase mais otimista, com relação a uma empresa, o preço das suas ações aumentam. Nesse valor do preço mais alto, fica mais fácil para a organização fazer o levantamento de seu capital e dessa forma estimular o investimento.

Neste contexto, os preços das ações desempenham um papel importante na alocação de capital nas economias de mercado, direcionando o capital.

\subsection{INVESTIMENTO EM CRÉDITO DE DESCARBONIZAÇÃO (CBIO)}

O regulador de petróleo e gás ANP publicou um regulamento para estabelecer metas de descarbonização para distribuidoras de combustíveis no programa RenovaBio, que se concentra no desenvolvimento da indústria brasileira de biocombustíveis para reduzir as emissões de carbono.

As metas individuais serão medidas com créditos de descarbonização chamados CBIOs e levarão em consideração a quantidade de emissões de gases de efeito estufa dos combustíveis que cada distribuidor vendeu no ano anterior.

O Conselho Nacional de Política Energética CNPE estabeleceu a meta de reduzir as emissões de carbono em I0\% até 2028. De acordo com a Agência Internacional de Energia Renovável (2020) o país tem atualmente a maior força de trabalho de biocombustíveis líquidos do mundo, com 832.00o empregos no setor no final de 2018.

No dia 27 de abril, foi dado o passo final para a plena operacionalização da Política Nacional de Biocombustíveis (RenovaBio), com a comercialização dos créditos de descarbonização (CBIO) na bolsa de valores brasileira. A partir de hoje, os produtores certificados de biocombustíveis poderão vender este certificado 
comercializável, com cada unidade correspondendo a uma economia total de uma tonelada de dióxido de carbono equivalente $\left(\mathrm{CO}_{2}\right.$ eq) em comparação com as emissões de combustíveis fósseis. As distribuidoras de combustíveis fósseis no Brasil, que têm metas anuais obrigatórias de redução de emissões de carbono a serem cumpridas, são as principais compradoras do CBIO. Os biocombustíveis importados também podem se beneficiar do esquema.

Instituído por lei em 2017, a implantação do programa ocorreu de acordo com o cronograma. Cerca de 200 unidades de produção foram certificadas com pontuações de ciclo de vida de carbono e critérios de sustentabilidade, e produtores de biocombustíveis foram autorizados a emitir CBIOs a partir de janeiro de 2020, ano em que os distribuidores de combustíveis fósseis também terão que começar a cumprir metas anuais para a matriz de combustível de transporte redução da intensidade do carbono ( BRASIL, 2017)

O programa RenovaBio é um passo importante para implementar o compromisso do Brasil com a Plataforma Biofuture de colocar em prática o conjunto certo de medidas para aumentar a bioenergia sustentável e promover soluções de baixo carbono no setor de transporte. É um exemplo-chave de implementação prática em nível nacional da Declaração da Visão do Biofuturo de 2017, endossada por 19 Países Membros da Plataforma Biofuturo, bem como dos objetivos definidos no Quadro de Governança da Plataforma, adotado no final de 2018.

De acordo com o Ministério de Minas e Energia do Brasil (2020) o programa RenovaBio deve fornecer aos consumidores opções de combustíveis mais sustentáveis, promover a diversificação contínua da matriz energética do Brasil e promover o investimento em processos de produção e conversão de matéria-prima mais eficientes e com baixo teor de carbono.

Para os produtores, a RenovaBio ganha ainda mais importância no contexto dos desafios enfrentados atualmente pelos produtores de biocombustíveis com a pandemia de COVID-ıg e a redução do consumo de combustíveis, pois proporciona uma renda adicional por seus serviços ao meio ambiente. 
Para os consumidores, os ganhos ambientais com a redução do consumo de combustíveis fósseis, que tornou o céu mais azulado, demonstram a necessidade de soluções permanentes que beneficiem toda a sociedade.

Nesse sentido, além da redução das emissões de $\mathrm{CO}_{2}$ em relação aos combustíveis fósseis, o etanol, em misturas de nível médio com a gasolina, tem um papel a desempenhar no Brasil na redução da poluição do ar local, especialmente por reduzir substancialmente as emissões de tubos de escape de particulados em suspensão matéria (PM2.5). PM2.5 é considerado um fator agravante para doenças respiratórias.

A agência estima que a produção de biodiesel no país dobrará na próxima década, chegando a II,I BL, o que pode criar I,4 milhão de empregos adicionais no setor.

Dessa forma, as empresas que se engajam na causa de sustentabilidade identificam a possibilidade de melhores resultados econômicos e estratégicos. Elas precisam se conscientizar que estes resultados não se viabilizam de imediato, eles requerem planejamento e organização de todos os passos para a interiorização da variável ambiental na organização, para só então, correr atrás da excelência ambiental, trazendo com isso vantagem competitiva (SERRÃO et al, 2014).

Conforme Moura (2004, p.53), a organização busca sempre melhorar seu desempenho para satisfazer melhor as necessidades dos consumidores, razão primordial para que a empresa sobreviva, pois apenas os consumidores satisfeitos adquirem serviços e produtos e se dispõem a pagar pela qualidade dos mesmos.

Os consumidores tradicionalmente, de acordo com Moura (2004), exigem três características para a aquisição de bens e serviços:

- Satisfação de suas necessidades e desejos dentro de um padrão de qualidade percebido;

- Preço compatível com o valor percebido para a oferta;

- Disponibilidade para entrega na quantidade e no tempo esperado.

As empresas que buscam esse comprometimento necessitam de mudanças na sua filosofia, com repercussão direta nas questões relativas a valores, estratégias, objetivos, produtos e programas por elas adotados (ZANATTA, 2017). 
Uma estratégia sustentável segue o modelo genérico de qualquer estratégia e considera para suas decisões, segundo Gravronski, (2009, p. 57) quatro fatores interdependentes: O contexto externo (ambiente, concorrência, legislação, etc.);

- As dimensões competitivas (preço, qualidade, etc.);

- As atividades da rede de valor (desenvolvimento, suprimento, produção, etc.);

- A aprendizagem/conhecimento (troca de conhecimento interno e externo, clima organizacional, etc.).

No caso da sustentabilidade como valor empresarial, segundo Brock (2012), é recomendável uma visão estratégica das empresas sobre os recursos pela observação em três dimensões:

I. Econômica - pelo aperfeiçoamento do sistema de produção, pela adoção da cadeia de valor, etc.;

2. Social - pela capacitação técnica e gerencial de seus colaboradores, pela criação de novos postos de trabalho, pela inclusão social, etc.;

3. Ambiental - pelas práticas de preservação e recuperação do meio ambiente, pelo aproveitamento de resíduos e efluentes, etc.

Figura I - Tripé da Sustentabilidade

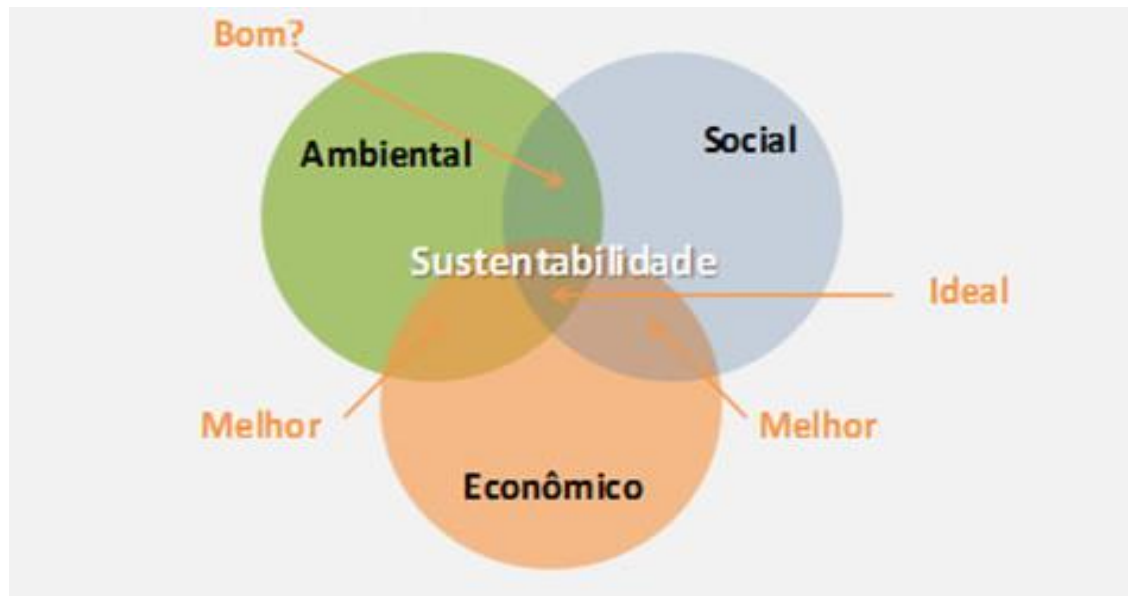

Fonte: Adaptado de Julianeli (20II) 
Considerando-se que, a sustentabilidade está no equilíbrio entre as três dimensões, haverá sempre o risco do desequilíbrio puxado pelo o lado econômico, face ao poder financeiro nas empresas, sempre que a incerteza exista e possa ocorrer, apesar do movimento dos stakeholders pela estabilização do tripé dimensional, principalmente porque trazem experiências externas ao ambiente organizacional que alavancam a competitividade.

Caberá à Gestão Ambiental Sustentável exercida pela empresa a manutenção do equilíbrio saudável. (BROCK, 2012). Na visão de Lipovetsky (2005), o indivíduo que toma decisões passou de um profissional manipulado e inconsciente para alguém que responde pelo bem-estar de todos.

Este alargamento do alcance da responsabilidade individual, que passou a incluir o impacto social dos atos praticados é um fato novo, criado na pós-modernidade pela invasão midiática, um maremoto de informações, em todas as telas disponíveis no mundo. O indivíduo hoje é responsável por si e pelo bem-estar de todos os outros. $\mathrm{Na}$ difusão digital da informação, muitas alterações ocorrem e o referencial é distorcido ou definitivamente perdido.

A “sociedade do espetáculo", conforme Guimarães et al. (20II), se apoia em competências e conhecimentos, a mão-de-obra passou a se confundir, com meios de produção. Assim, o uso adequado da competência e do conhecimento individual em um processo operacional, produtivo ou administrativo é que gera a riqueza e agrega valor aos produtos e serviços entregues ao mercado.

A ética das empresas, conforme Passos (2012) está no alinhamento dessas competências e conhecimentos com um conjunto de normas consideradas indispensáveis, que são as formadoras da cultura da organização, portanto apoiandose no domínio dos critérios de tomada de decisão utilizados por seus colaboradores.

\section{CONSIDERAÇÕES FINAIS}

Este trabalho tem como objetivo central de demonstrar os fatores que envolvem o investimento em Crédito de Descarbonização (CBIO). E os objetivos específicos foram: desenvolver um construto dos resultados das análises, de diferentes autores, efetuadas e publicadas, sobre o tema: economia e sustentabilidade, a partir de pesquisas 
aplicadas ao ambiente organizacional e suas relações com o mercado, no sentido da obtenção de caminhos para a conquista de vantagens competitivas para as empresas.

Através deste estudo pode-se constatar que, o advento do programa RenovaBio é um passo importante para implementar o compromisso do Brasil com a Plataforma Biofuture de colocar em prática o conjunto certo de medidas para aumentar a bioenergia sustentável e promover soluções de baixo carbono no setor de transporte.

Para os consumidores, os ganhos ambientais com a redução do consumo de combustíveis fósseis, que tornou o céu mais azulado, demonstram a necessidade de soluções permanentes que beneficiem toda a sociedade. Dessa forma, as empresas que se engajam na causa de sustentabilidade identificam a possibilidade de melhores resultados econômicos e estratégicos.

Elas precisam se conscientizar que estes resultados não se viabilizam de imediato, eles requerem planejamento e organização de todos os passos para a interiorização da variável ambiental na organização, para só então, correr atrás da excelência ambiental, trazendo com isso vantagem competitiva.

\section{REFERENCIAS}

CASTILHO.A.M. Criatividade do processo de coaching. Ed. Trevisan, São Paulo, 2013.

DEBORD, G. A sociedade do espetáculo. Rio de Janeiro: Contraponto, 1997.

DIAS, M. O. Ética, Organização e Valores Ético-Morais em Contexto Organizacional, Gestão e Desenvolvimento, Rev. Gestão e Desenvolvimento v.22, p.89II3, 2014.

DIAS, R. Gestão Ambiental - Responsabilidade Social e Sustentabilidade. $3^{\text {a }}$. ed. São Paulo: Atlas. 2017.

DONAIRE, D. Gestão ambiental na empresa. São Paulo: Atlas, I999.

DRUMMOND.S.V. Confiança e Liderança nas organizações, Ed.Cengage Learning, São Paulo,2007

FUKUYAMA, F. Confiança: as virtudes sociais e a criação da prosperidade. Trad. Alberto Lopes. Rio de Janeiro: Rocco, 1996. 
FUNDAÇÃO NACIONAL DA QUALIDADE - FNQ. Sistema de Indicadores. Disponível em: 〈http://www.fnq.org.br/informe-se/publicacoes $\rangle$. Acesso em: I5/II/2020.

GAVRONSKI, I. Estratégia de Operações Sustentáveis: Produção; Suprimentos; Logística e Engenharia Alinhados com a Sustentabilidade Corporativa. 2009. Tese de Doutorado, Universidade Federal do Rio Grande do Sul, Porto Alegre, 2009.

GIBSON, J. L.; IVANCEVICH, J. M.; DONNELLY JR, J. H. e KONOPASKE, R. Organizações: Comportamento, Estrutura e Processos. São Paulo: McGraw-Hill. 2006.

GUIMARÃES, R. C., LOVISON, A.M. e BUCCO, L. B. O indivíduo ético na sociedade do espetáculo. Comunicação e Sociedade, ano 32, n. 55, p. 257-277. 2011.

LAASCH, O.; CONAWAY, R. N. Fundamentos da Gestão Responsável: Sustentabilidade, Responsabilidade e Ética. São Paulo: Cengage Learning. 2016.

LIPOVETSKY, G. A Sociedade Pós-Moralista: o crepúsculo do dever e a ética indolor dos novos tempos democráticos. São Paulo: Manole. 2005.

MOURA, L. A. A. Qualidade e Gestão Ambiental. São Paulo: Juarez de Oliveira, 2004 .

PASSOS, E. Ética nas organizações. São Paulo: Atlas, 2012.

PORTER, M. E. Estratégia competitiva: técnicas para análise de indústrias e da concorrência. Rio de Janeiro: Elsevier, 2004.

REZENDE, F. P. e CASTRO, J. M. P. Ética na Empresa: o Indivíduo e Suas Relações no Trabalho. Anais do SEGeT - VIII Simpósio de Excelência em Gestão e Tecnologia, 200Ir.Disponível em: 〈https://www.aedb.br/seget/arquivos/artigosil/30514556.pdf〉. Acesso em: 28/o4/ 2019. of Ma- nagement Review, v. 23. n. 3, p. 393, jul. 1998. Disponível em: 〈http://search.epnet.com/di- rect.asp?an=926617\&db=buh $>$. Acesso em: 30.11.2020.

SENNETT, R. A corrosão do caráter e consequências pessoais do trabalho no novo capitalismo. Rio de Janeiro/São Paulo: Record, 1999.

SERRÃO, M.; ALMEIDA, A. E CARESTIATO, A. Sustentabilidade - uma questão de todos nós. Rio de Janeiro: SENAC Nacional, 2014.

SROUR, R. H. Ética Empresarial: O Ciclo Virtuoso do Negócio. São Paulo: Campus, 2008. 
STOFFEL. J. A. e COLOGNESE, S.A. O desenvolvimento sustentável sob a ótica da sustentabilidade multidimensional. Revista FAE, v. 18, n. 2, p.18-37. 2015.

TAJRA.S.F; SANTOS.N. Planejamento e Liderança : Conceitos estratégicos, 2014.

TACHIZAWA, T. Gestão Ambiental e Responsabilidade Social Corporativa. São Paulo: Atlas. 20II.

TAMAYO, A; MENDES, A. M.; \& PAZ, M. G. Inventario dos valores organizacionais. Revista Estudos de Psicologia, v.5, n.2, p.289-315, 2000.

ZANATTA, P. Gestão Ambiental e Desenvolvimento Sustentável. Revista de Gestão ¿ Sustentabilidade Ambiental, v. 6, n. 3, p. 296-312.2017.

ZUCKER, L. G. et al. Collaboration structure and information dilemmas in biotechnology: organizational boundaries as trust production. In: KRAMER, R. M.; TYLER, T. R. (eds.). Trust in organizations: frontiers of theory and research. Thousand Oaks, CA: Sage,1996, p. 90-II3. 